22. P. E. Kolattukudy, Chemistry and Biochemistry of Natural Waxes (Elsevier, Amsterdam, 1976).

23. G. Rieley et al., Nature 352, 425 (1991).

24. N. Ohkouchi, K. Kawamura, A. Taira, Org. Geochem. 27, 173 (1997).

25. Y. Huang, F. A. Street-Perrott, R. A. Perrott, P. Metzger, G. Eglinton, Geochim. Cosmochim. Acta 63 1383 (1999).

26. Y. Huang, L. Dupont, M. Sarnthein, J. M. Hayes, G. Eglinton, Geochim. Cosmochim. Acta 64, 3505 (2000).

27. E. Schefuss et al., Geochim. Cosmochim. Acta 67 , 1757 (2003)

28. M. H. Conte, J. C. Weber, Nature 417, 639 (2002)

29. J. M. Hayes, Mar. Geol. 113, 111 (1993).

30. M. L. Fogel, L. A. Cifuentes, in Organic Geochemistry M. H. Engel, S. A. Macko, Eds. (Plenum, New York, 1993), pp. 73-98.

31. K. H. Freeman, L. A. Colarusso, Geochim. Cosmochim. Acta 65, 1439 (2001).

32. Materials and methods are available as supporting material on Science Online.

33. M. Friedrich et al., Radiocarbon, in press.

34. K. A. Hughen, J. R. Southon, C. J. H. Bertrand, B. Frantz, P. Zermeno, Radiocarbon, in press.

35. Comparing $\delta^{13} \mathrm{C}$ for $C_{16}$ versus $C_{32} n$-alkanoic acids shows no significant correlation (slope $=0.11$ and correlation coefficient $r=0.14$ )

36. The $A C L$ index used here is confined to the most abundant homologs and is defined as $\Sigma\left(i X_{i}\right) / \Sigma X_{i}$ where $X=$ abundance and $i=24,26$, and 28 carbon atoms.

37. It is possible that the range of $\delta^{13} \mathrm{C}$ values for arid $\mathrm{C}_{4}$ versus humid $\mathrm{C}_{3}$ plant populations lie closer together than the respective $A C L$ distributions. In particular, plants using crassulacean acid metabolism (CAM) metabolism exhibit $\delta^{13} \mathrm{C}$ values intermediate between those for $C_{3}$ and $C_{4}$ plants $(29,30)$, and may have been present during the Younger Dryas transition. Although $\delta^{13} \mathrm{C}$ distributions for modern $\mathrm{C}_{3}$ and $\mathrm{C}_{4}$ plants are well known, comparable measurements for $\mathrm{ACL}$ indices have not been made.

38. R. S. Bradley, in Paleoclimatology (Academic Press, San Diego, CA, 1999), chap. 9, pp. 358-396.

39. D. Rind, D. Peteet, W. S. Broecker, A. Mclntyre, W Ruddiman, Clim. Dyn. 1, 3 (1986).

40. K. M. Yarincik, R. W. Murray, L. C. Peterson, Paleoceanography 15, 210 (2000).

41. African $n$-alkanoic acid leaf waxes during Glacial and Younger Dryas climates were almost certainly offset from the Holocene values shown in Fig. 2 for both $\delta^{13} \mathrm{C}$ and $\mathrm{ACL}$ indices. Isotopic data for $n$ alkane leaf waxes off northwest Africa show $-4 \%$ o shift from the Last Glacial Maximum to the Holocene (48). Any similar Glacial shift in $n$ alkanoic acid $\delta^{13} \mathrm{C}$ would place the African data in Fig. 2 even farther from the Cariaco data and necessitate an unrealistically large change in $\mathrm{ACL}$ to place the African data as an end member on the Cariaco mixing line. Similarly, if African source regions changed, the new region would require a drier $\mathrm{ACL}$, but wetter or unchanged $\delta^{13} \mathrm{C}$ signal, inconsistent with the $\delta^{13} \mathrm{C}-\mathrm{ACL}$ relationships seen in African leaf waxes (27). The simplest explanation, supported by local pollen data $(13,14)$, is that Cariaco leaf wax data represent changes in local vegetation during deglacial climate changes.

42. C. B. Ramsey, J. van der Plicht, B. Weninger, Radiocarbon 43, 381 (2001)

43. The biomarker records were used at their original 20- to 40-year sampling resolution for crosscorrelation with gray scale and $\Delta^{14} \mathrm{C}$. High-resolution gray-scale data were averaged and $\Delta^{14} C$ records were interpolated and resampled to provide even annual resolution. For comparison with gray-scale data, $\Delta^{14} \mathrm{C}$ was used at its original 10 to 15 -year resolution.

44. The lag calculation is dependent on cross-correlations using all data points within the interval of overlap, rather than the timing of the initial change recorded between data points (42). Therefore, although biomarker sampling resolution is $\sim 40$ years during the Younger Dryas onset, the transition itself lasted $\sim 200$ years, encompassing five or six data points, and the cross-correlation can be evaluated uniquely for each annual time step. Similarly, the biomarker sample resolution during the Glacial/Bølling transition is $\sim 20$ years, providing two or three data points within the duration of the shift. However, the biomarker resolution across the Younger Dryas termination is low ( $\sim 40$ years) relative to the climate shift, and the transition appears to occur between data points; thus, the calculated vegetation lag of $25 \pm 15$ years must be considered a minimum estimate. The robustness of these analyses relies on the assumption that the lowerresolution proxy data are not systematically offset above or below the true trend (32).

45. It is possible that some leaf waxes may be transported to the Cariaco basin by rivers, and thus the apparent lag could in part reflect the residence time of leaf waxes during riverine transport. However, leaf waxes are predominantly ablated and transported via eolian processes $(22,26-28)$, and thus if the vegetation change were synchronous with local climate there should be an immediate response in leaf waxes carried by eolian transport following an abrupt climate shift, with a slower rise due to fluvial input of leaf waxes following the climate change. However, the timing of rapid change in leaf waxes distinctly lags the rapid changes in climate, especially during the Younger Dryas onset (Fig. 3), in agreement with an overall lag of $\sim 50$ years.

46. W. S. Broecker, Science 300, 1519 (2003)

47. T. M. Marchitto, W. B. Curry, D. W. Oppo, Nature 393 , 557 (1998)

48. M. Zhao et al., Org. Geochem. 31, 919 (2000).

49. We thank N. Ohkouchi and P. Huybers for technical expertise and three anonymous reviewers for helpful discussions that improved this paper. Funding for this work was provided by the Frank and Lisina Hoch Endowed Fund and by the Woods Hole Oceanographic Institution (WHOI) Director's General Discretionary Fund. This is WHOI contribution no. 11112.

\section{Supporting Online Material}

www.sciencemag.org/cgi/content/full/1092995/DC1

Materials and Methods

Figs. S1 and S2

Data available at the World Data Center-A for Paleoclimatology (www.ncdc.noaa.gov)

27 October 2003; accepted 11 May 2004

Published online 20 May 2004

$10.1126 /$ science 1092995

Include this information when citing this paper.

\title{
Antarctic Timing of Surface Water Changes off Chile and Patagonian Ice Sheet Response
}

\author{
Frank Lamy, ${ }^{1,2 *}$ Jérôme Kaiser, ${ }^{2}$ Ulysses Ninnemann, ${ }^{3}$ \\ Dierk Hebbeln, ${ }^{2}$ Helge W. Arz, ${ }^{1}$ Joseph Stoner ${ }^{4}$
}

\begin{abstract}
Marine sediments from the Chilean continental margin are used to infer millennial-scale changes in southeast Pacific surface ocean water properties and Patagonian ice sheet extent since the last glacial period. Our data show a clear "Antarctic" timing of sea surface temperature changes, which appear systematically linked to meridional displacements in sea ice, westerly winds, and the circumpolar current system. Proxy data for ice sheet changes show a similar pattern as oceanographic variations offshore, but reveal a variable glacier-response time of up to $\sim 1000$ years, which may explain some of the current discrepancies among terrestrial records in southern South America.
\end{abstract}

Resolving the origin and consequences of the millennial-scale climate changes evident during the last glacial period, and particularly during the last deglaciation, is a cardinal challenge of current paleoclimate research. A comprehensive understanding of such climate changes is invaluable for validating and improving prognostic climate models. In the North Atlantic region, large and abrupt temperature changes are clearly documented at

${ }^{1}$ GeoForschungsZentrum-Potsdam, Telegrafenberg, 14473 Potsdam, Germany. ${ }^{2}$ Deutsche Forschungsgemeinschaft (DFG) Research Center Ocean Margins, Klagenfurter Strasse, 28359 Bremen, Germany. ${ }^{3}$ Department of Earth Sciences and Bjerknes Centre for Climate Research, University of Bergen, Allégaten 41, 5007 Bergen, Norway. ${ }^{4}$ Institute of Arctic and Alpine Research, University of Colorado, Boulder CO, 80309-0450, USA

*To whom correspondence should be addressed. Email: flamy@gfz-potsdam.de intervals of $\sim 5$ to 10 and $\sim 1$ to 4.5 thousand years (named the Heinrich and Dansgaard-Oeschger events, respectively). The origins of these events are commonly construed to be linked to reorganizations in Atlantic thermohaline circulation (THC) (1). More recently, abrupt millennial-scale climatic oscillations have been recognized in many places around the globe. Their source is also postulated to be variations in the North Atlantic ocean-climate system propagating by means of global oceanic and atmospheric feedbacks (2).

Recent modeling studies, however, indicate that the tropics and the southern high latitudes may also play an active role in initiating rapid climate change $(3,4)$. For example, it has been shown that rapid climate oscillations may originate from the tropical Pacific, potentially involving a long-term modulation of interannual-todecadal climate changes of the eastern trop- 
ical Pacific El Niño-Southern Oscillation (ENSO) (3). This tropical driver hypothesis is strengthened by recent proxy evidence from the tropical Pacific, suggesting substantial millennial variability that likely involves long-term ENSO changes $(5,6)$. A high-southern latitude control is indicated by new modeling results $(4,7)$, which imply that abrupt climate changes known from the North Atlantic region during Termination 1 might well be triggered by gradual changes in southern high latitudes.
Fig. 1. Map of southern to central Chile and the adjacent southeast Pacific showing location of ODP Site 1233 in relation to oceanographic features [PCC, Peru-Chile Current; CFW, Chilean Fjord Water (30)], modern mean annual SSTs (in degrees Celsius), and the maximum extension of the PIS, adapted from (20). LGM, last glacial maximum.

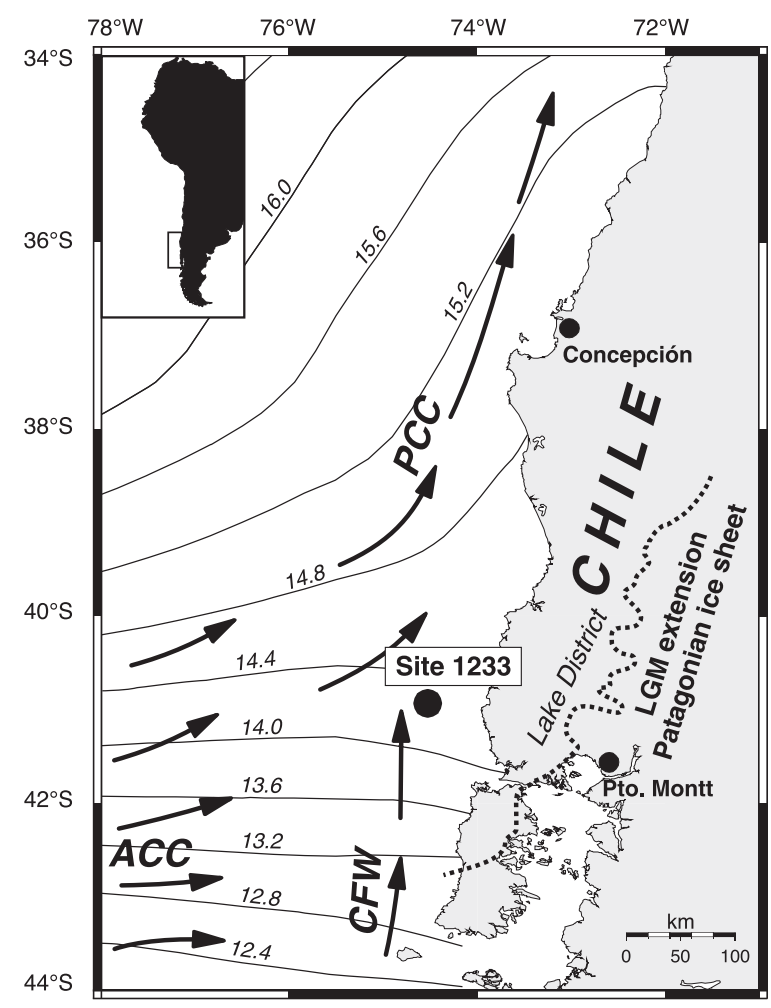

Fig. 2. Compilation of paleoclimatic data sets from the Southern Hemisphere mid-latitudes (24) compared with Antarctic and Greenland ice core records ( 8 to $50 \mathrm{kyr}$ B.P.). (A) Diatom-based sea ice reconstruction from South Atlantic core TN 057-13 (27). (B) $\mathrm{Mg} / \mathrm{Ca}$ SST record from the Southwest Pacific (15). (C) Oxygen isotope record of Globigerina bulloides based on core RC11-83 from the South Atlantic, primarily reflecting SST (25). (D) Alkenone SST record from ODP Site 1233 (this study). (E) Oxygen isotope $\left(\delta^{18} \mathrm{O}\right)$ record of the Byrd ice core, Antarctica (8). (F) Oxygen isotope record of the GISP2 ice core, Greenland (31). Gray bars mark age and approximate duration of the Younger Dryas (YD) and Heinrich $(H)$ events (based on GISP2 ages). VPDB, Vienna Peedee Belemnite; VSMOW, Vienna standard mean ocean water.

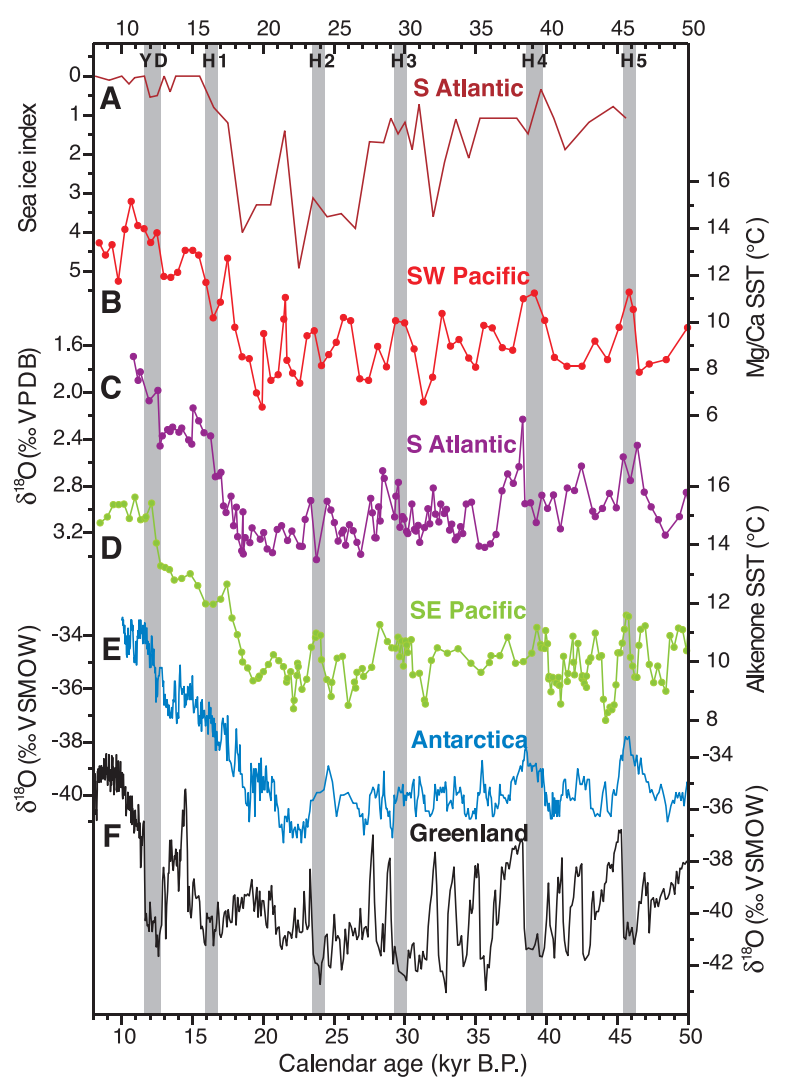

Most studies of interhemispheric climate change focus on comparing Northern Hemisphere records to Antarctic ice core data, particularly from the Byrd ice core, which has the most reliable age model (8). These comparisons suggest asynchronic changes between the Northern and Southern Hemisphere (8), consistent with the "bipolar see-saw concept" of Southern Hemisphere warming in response to reduced North Atlantic THC $(9,10)$. On the other hand, terrestrial data from midlatitude South America are still discussed controversially because they indicate both interhemispheric synchrony (11-13) and asynchrony (14). Even more puzzling are new surface ocean proxy records from the southwest Pacific implying that the coupling of oceanographic changes in the midsouthern latitudes and Antarctica might have changed with time (15).

Here, we present new records of surface ocean conditions in the southernmost Peru-Chile Current and associated changes in the extent of the Patagonian ice sheet (PIS) in adjacent southern Chile based on well-dated marine sediments recovered at Ocean Drilling Program (ODP) Site 1233 from the southern Chilean continental margin (16) (Fig. 1). Continental paleoenvironmental records show that this region reacted very sensitively to rapid fluctuations in climate $(11-13,17)$. However, so far it has proven difficult to compare such records unambiguously to those from the Northern Hemisphere because of discontinuities, inadequate temporal resolution, and limitations in dating.

Sediments at Site 1233 are characterized by lithologically homogeneous finegrained terrigenous material with minor amounts of well-preserved biogenic components suitable for paleoceanographic studies (16). We focused on the time interval from 8 to 50 thousand calendar years before present (kyr B.P.), which is dated by $20{ }^{14} \mathrm{C}$ accelerator mass spectrometry (AMS) dates and further paleomagnetic evidence (18). Resulting sedimentation rates are extraordinarily high ( 1 to $3 \mathrm{~m} / \mathrm{kyr}$ ) because of strong fluvial discharge in response to heavy continental rainfall in southern Chile (19) and the proximity to the PIS, which advanced toward the Chilean Lake District (directly onshore Site 1233; Fig. 1) during the last glacial period (20) and provided terrigenous material by means of glacial erosion.

Our primary proxy record is the alkenonebased sea surface temperature (SST) reconstruction at Site 1233 (18), indicating a $\sim 6^{\circ} \mathrm{C}$ SST change over Termination 1 and millennial-scale variations on the order of $\sim 2^{\circ}$ to $\sim 3^{\circ} \mathrm{C}$ during the glacial period (Fig. 2D). During Termination 1, two major 
warming steps were recorded $\left(\sim 3^{\circ} \mathrm{C}\right.$ from 19.2 to $17.4 \mathrm{kyr}$ B.P. and $\sim 2^{\circ} \mathrm{C}$ from 12.7 to 12.1 kyr B.P.), the last one of which falls into the first half of the Younger Dryas (Fig. 3B). This pattern is notably similar to the deglacial warming record of the Byrd ice core (8) (Fig. 3A). For the glacial interval (20 to $50 \mathrm{kyr}$ B.P.), a number of millennial-scale SST fluctuations also appear to correlate to Antarctic temperature changes (Fig. 2, D and E), suggesting a direct link from SST changes in the southeast Pacific to climate fluctuations in high southern latitudes.

The large amplitude of SST variations over Termination 1 as well as on millennial time scales during the last glacial period suggests substantial oceanographic changes. The most plausible explanation is a northward translation of the Antarctic Circumpolar Current (ACC) during cold periods enhancing the influence of subantarctic water masses at Site 1233. Today, SST gradients within the northernmost $\mathrm{ACC}$ are very large (Fig. 1) and intimately linked to the northern margin of the westerly wind belt, making this region very sensitive to latitudinal shifts of atmospheric and oceanographic circulation, which results in the large signal in our proxy data. The position of the westerlies is controlled by the location of the subpolar low-pressure belt and the strength and position of the southeast Pacific anticyclone (21), allowing the potential for both high-(southern) latitude and tropical Pacific forcing mechanisms. A tropical forcing could involve a long-term modulation of ENSO (3), which may have a substantial influence on the position of the westerlies through a modulation of the strength of the southeast Pacific anticyclone. There is some evidence that ENSO operated at least during the last $130 \mathrm{kyr}$ (22) and that millennial-scale oscillations would likely reveal a "Greenland pattern" of climate change $(5,6)$, which our data cannot support. On the other hand, a new SST record from the Sulu Sea does not indicate substantial change of zonal SST gradients in the tropical Pacific across the Bølling-Allerød/Younger Dryas climate reversals, raising doubts about whether interannual (ENSO) variability is a good analog for longer term climate change (23).

Our data clearly suggest that millennialscale climate changes documented in Antarctic ice cores extended into the Southern Hemisphere mid-latitudes and affected major oceanographic (i.e., the ACC) and atmospheric (the Westerlies) circulation patterns. Within the uncertainties of age models (24), these changes appear quasihemisphere-wide, as shown by a comparison to a $\mathrm{Mg} / \mathrm{Ca} \mathrm{SST}$ record from the Southwest Pacific (15) (Fig. 2B) and a planktic foraminifera oxygen isotope record from the South Atlantic (25) (Fig. 2C). Although the sense and timing of our temperature changes are generally consistent with the bipolar see-saw mechanism $(8-10)$ [i.e., cold North Atlantic temperatures during Heinrich events parallel increasing SST in the Southern Hemisphere mid-latitudes (Fig. 2)], model simulations of THC changes do not show a substantial response in the southeast Pacific (26). Thus, it is equally plausible that the quasi-Southern Hemisphere-wide millennial-scale pattern emerging in Pacific and Atlantic records is of Southern Hemisphere origin. Recent modeling studies suggest that comparatively slow climate changes around Antarctica might trigger abrupt events in the North Atlantic realm, most likely involving changes in sea ice extent and salinities in the Southern Ocean $(4,7)$. Diatom-based sea ice reconstructions from the Atlantic sector of the Southern Ocean (Fig. 2A) (27) do indeed parallel the SST changes in the Pacific and show reduced sea ice extent during periods of warmer Southern Hemisphere mid-latitude SSTs.

The Antarctic timing apparent in our SST record is distinct from that observed in terrestrial glaciological and palynological data from the Chilean Lake District directly onshore Site 1233, which more closely follow the Northern Hemisphere pacing and have been used to argue for interhemispheric synchrony during both the glacial period (12) and deglaciation (11, 13). Site 1233

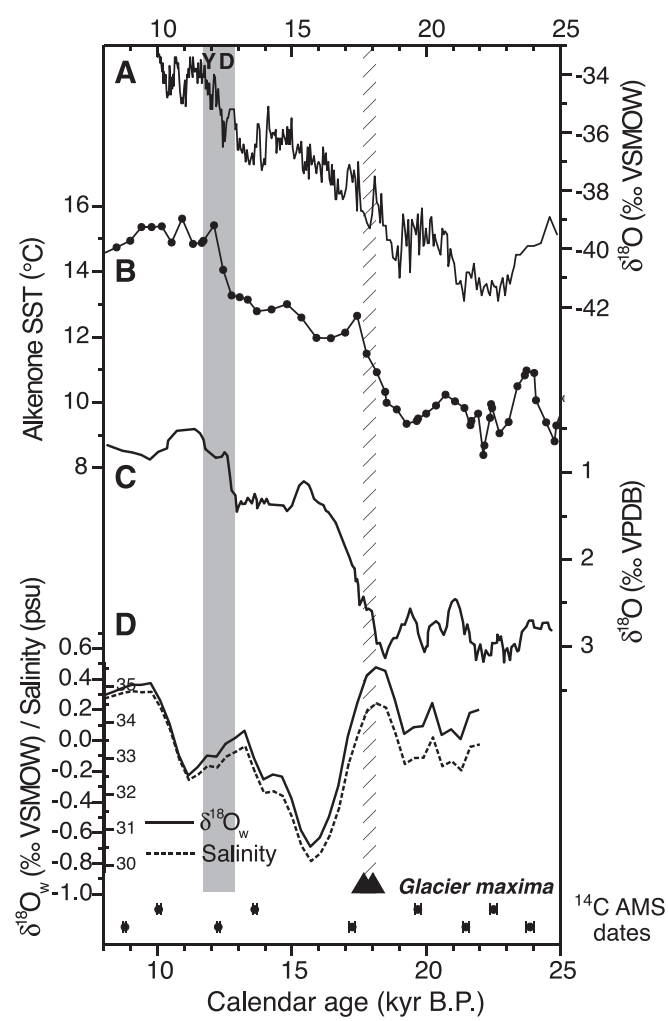

offers the exceptional opportunity to compare continental and marine paleoenvironmental changes within the same well-dated archive. The site is located in an ideal position to monitor PIS extent variations by recording compositional changes in the regional terrigenous sediment input to the continental margin. For this purpose, we use the $\mathrm{Fe}$ content of the bulk sediment measured at subdecadal resolution (18). For the Holocene record of core GeoB 3313-1 from the same location, changing Fe contents have been related to a varying contribution of Andean (Fe-rich) versus Coastal Range (Fe-poor) source rocks ultimately controlled by continental rainfall changes (19). Glacial erosion processes strongly enhanced the glaciofluvial sediment flux from Fe-rich basaltic volcanics in the Andes during the last glacial period, and ice sheet advances provided more Fe-rich material, which was subsequently transported to the continental margin by rivers. This scenario is supported by extensive geomorphological mapping and dating of moraines that documented pronounced PIS variability during the late glacial period (20). Three of four major ice maxima correlate, within the limitations of dating (24), to maxima in our $\mathrm{Fe}$ record (Fig. 4). Thus, our proxy of glaciofluvial sediment input provides a continuous record of PIS variability for a major part of the last glacial period.

A modeling study of PIS changes during the late glacial period points to a close dependence of ice extent on offshore SSTs

Fig. 3. Deglacial paleoceanographic records from Site 1233. (A) Oxygen isotope record of the Byrd ice core, Antarctica (8). (B) Alkenone SST record. (C) Oxygen isotope record of the planktic foraminifera Globigerina bulloides (five-point moving average). (D) Salinity reconstruction (three-point moving average). $\delta^{18} \mathrm{O}_{w}$ oxygen isotope composition of seawater; VSMOW, Vienna standard mean ocean water; psu, practical salinity unit. Age control points are shown below. Gray bar marks the Younger Dryas (YD) event and hatched bar marks the final PIS maxima before rapid deglaciation [after $(20,24)]$. 
and suggests a $6^{\circ} \mathrm{C}$ SST lowering in the southeast Pacific off southern Chile during the regional ice maximum (28), exactly matching our alkenone SST reconstructions at Site 1233. In addition, SST fluctuations of $\sim 2^{\circ}$ to $\sim 3^{\circ} \mathrm{C}$ during the glacial period follow a pattern notably similar to the variations in Fe (Fig. 4). This comparison demonstrates that the repeated perturbations in offshore SST between $\sim 20$ and $50 \mathrm{kyr}$ B.P. are regularly accompanied by substantial changes in onshore ice extent - seemingly confirming the sensitivity of the northern PIS limb to oceanographic variations offshore observed in models (28).

Though the patterns of the Fe and paleoSST records are very similar, SST changes lead the Fe variations by up to $\sim 700$ years (Fig. 4 and figs. S2 and S3). The offset is largest between $\sim 20$ and $40 \mathrm{kyr}$ B.P. and disappears in the earliest part of our record. On one hand, this offset may indicate that the relation of Fe changes to glacial dynamics is not as straightforward as we assume. For example, it is conceivable that a glacier retreat in response to rising SSTs would initially result in enhanced sediment and thus Fe output, given that material in storage is released as the ice margin retreats. On the other hand, the independently dated glacier maxima (20) correlate in most cases to periods of rising SST (Fig. 4) particularly the well-dated glacier maxima between $\sim 18.0$ to $17.7 \mathrm{kyr}$ B.P. $(20,24)$ that occurred after SSTs had already been rapidly increasing for $\sim 1000$ years (Fig. 4). Additional support for a delayed ice sheet response comes from our reconstruction of paleosalinity over Termination 1 (18). The substantial decrease in salinities from $\sim 17.8$ to 15.8 kyr B.P. (Fig. 3D) suggests that the PIS was wasting rapidly after the last glacier maxima inferred from terrestrial studies (20). During this period, Fe contents remain high and most likely reflect strong fluvial erosion of the rapidly exposing glacial deposits and thereafter decrease toward the Holocene when they become controlled by rainfall (19). Taken together, these observations suggest a substantial time lag between climate forcing and PIS response, assuming that the atmospheric system responds roughly synchronously to changes in SSTs, which is reasonable for the extremely maritime climate conditions in southern Chile. The changing time lag along the record suggests a possible relationship to ice sheet size. Though not precisely dated, terrestrial studies show that the PIS was substantially reduced in size during early marine isotope stage 3 (20), consistent with the disappearance of the delay before $40 \mathrm{kyr}$ B.P. The largest lag is observed for the decay of ice after its maximum extent before the deglaciation.

Our records provide an important advance toward a better understanding of interhemispheric climate change during the last glacial period and deglaciation, which has been hampered by the lack of high-resolution paleoceanographic records from the South Pacific region (29). Together with proxy evidence from the southwestern Pacific and Atlantic, our data suggest a quasi-Southern Hemisphere-wide millennial-scale pattern of atmosphere-ocean changes in phase with Antarctic ice core records, providing important constraints for the optimization of climate models. The apparent climate inertia in the PIS and its variable influence on terrestrial sites whose climate may be strongly influenced by changes in the size and proximity of the ice sheet could, on the other hand, explain some of the current discrepancies among terrestrial records in southern South America, e.g., during Termination $1(13,14)$.

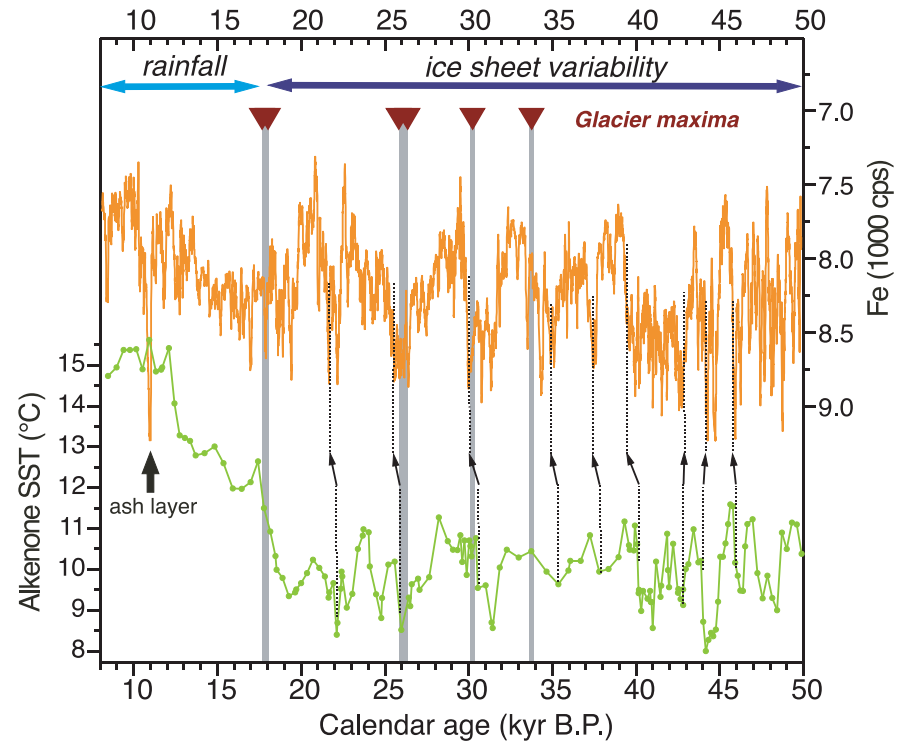

\section{References and Notes}

1. S. Rahmstorf, Nature 419, 207 (2002).

2. A. H. L. Voelker, Quat. Sci. Rev. 21, 1185 (2002).

3. M. A. Cane, Science 282, 59 (1998).

4. G. Knorr, G. Lohmann, Nature 424, 532 (2003).

5. A. Koutavas, J. Lynch-Stieglitz, T. M. Marchitto, J. P. Sachs, Science 297, 226 (2002).

6. L. Stott, C. Poulsen, S. Lund, R. Thunell, Science 297, 222 (2002).

7. A. J. Weaver, O. A. Saenko, P. U. Clark, J. X. Mitrovica, Science 299, 1709 (2003).

8. T. Blunier, E. J. Brook, Science 291, 109 (2001).

9. T. F. Stocker, Science 282, 61 (1998).

10. W. S. Broecker, Paleoceanography 13, 119 (1998).

11. G. H. Denton et al., Geogr. Ann. Ser. A Phys. Geogr. 81A, 107 (1999).

12. T. V. Lowell et al., Science 269, 1541 (1995).

13. P. I. Moreno, G. L. Jacobson, T. V. Lowell, G. H. Denton, Nature 409, 804 (2001).

14. K. D. Bennett, S. G. Haberle, S. H. Lumley, Science 290, 325 (2000).

15. K. Pahnke, R. Zahn, H. Elderfield, M. Schulz, Science 301, 948 (2003).

16. Shipboard Scientific Party, Leg 202 Summary, in Proc. ODP Init. Rep., A. C. Mix et al., Eds. (Ocean Drilling Program, College Station, TX, 2003), vol. 202, pp. $1-145$.

17. L. Heusser, C. Heusser, A. Kleczkowski, S. Crowhurst, Quat. Res. 52, 154 (1999).

18. Materials and methods are available as supporting material on Science Online.

19. F. Lamy, D. Hebbeln, U. Rohl, G. Wefer, Earth Planet. Sci. Lett. 185, 369 (2001).

20. G. H. Denton et al., Geogr. Annal. Ser. A Phys. Geogr. 81A, 167 (1999).

21. R. S. Cerveny, in Climates of the Southern Continents: Present, Past and Future, J. E. Hobbs, J. A. Lindesay, H. A. Bridgman, Eds. (Wiley, New York, 1998), Pp. 107-134.

22. A. W. Tudhope et al., Science 291, 1511 (2001).

23. Y. Rosenthal, D. W. Oppo, B. K. Linsley, Geophys. Res. Lett. 30, 11 (2003).

24. ${ }^{14} \mathrm{C}$-based age models of all records shown in this paper have been recalculated with Calpal 2004; details in (18).

25. U. S. Ninnemann, C. Charles, D. Hodell, in Mechanisms of Global Climate Change at Millennial Time Scales, P. U. Clark, R. S. Webb, L. D. Keigwin, Eds. (American Geophysical Union, Washington, DC, 1999), pp. 94-112.

26. A. Ganopolski, S. Rahmstorf, Nature 409, 153 (2001).

27. J. B. Stuut, X. Crosta, K. Van der Borg, R. Schneider, Geology, in press.

28. N. R. J. Hulton, R. S. Purves, R. D. McCulloch, D. E. Sugden, M. J. Bentley, Quat. Sci. Rev. 21, 233 (2002).

29. T. F. Stocker, Science 297, 1814 (2002).

30. P. T. Strub, J. M. Mesias, V. Montecino, J. Ruttlant, S. Salinas, in The Global Coastal Ocean: Regional Studies and Syntheses, A. R. Robinson, K. H. Brink, Eds. (Wiley, New York, 1998), pp. 273-315.

31. P. M. Grootes, M. Stuiver, J. W. C. White, S. Johnsen, J. Jouzel, Nature 366, 552 (1993).

32. We thank A. Mix and R. Tiedemann, the Shipboard Scientific Party, captain, and crew of ODP Leg 202; U. Röhl for support in x-ray fluorescence core scanning; N. Hulton for discussions on Patagonian ice sheet changes; and G. Haug for helpful comments. Supported by the DFG (Projekt HE 3412/1-2) and the Bjerknes Centre for Climate Research. This research used samples provided by the ODP. The ODP is sponsored by NSF and participating countries under management of Joint Oceanographic Institutions (JOI), Inc

Supporting Online Material www.sciencemag.org/cgi/content/full/304/5679/1959/ DC1

Materials and Methods

Figs. S1 to S3

Table S1

References

15 March 2004; accepted 14 May 2004 